\title{
Analysis about The Choice of The Mode of Social Cooperative Governance
}

\author{
BingRui Liu ${ }^{1, a}$, XiuRong Zhang ${ }^{2, b, *}$ \\ ${ }^{1}$ School of humanities \& Economic management of China University of Geosciences,Beijing,China \\ ${ }^{2}$ School of Education in Ideology and Politics of China University of Geosciences,Beijing,China \\ asxxzliujie@126.com, ${ }^{b} 1557516060 @ q q . c o m$ \\ ${ }^{*}$ Corresponding author
}

\begin{abstract}
Selecting the development of the mode of social cooperative governance as its starting point, this thesis holds that there are three reasons to choose this mode: low efficiency of the traditional governance mode, significant developments of social organizations, and policies of the Chinese Communist Party. However, three obstacles counteract its implementation: backwardness of the concept of social governance, insufficient development of the society, and unsoundness of the governance mechanism. Thus, this thesis constructs the social cooperative governance mode under the following three conditions: transforming the notion of traditional governance, cultivating the subject and innovating new mechanism of cooperative governance.
\end{abstract}

Keywords: Social Cooperation, Governance Mode, Current Dilemma, Exploration of paths.

\author{
社会协同治理模式选择的探析 \\ 刘秉瑞, ${ }^{1, a}$ ，张秀荣 $2, \mathrm{~b}$, , \\ ${ }^{1}$ 中国地质大学 (北京) 人文经管学院, 海淀, 北京, 中国 \\ ${ }^{2}$ 中国地质大学 (北京) 思想政治教育学院, 海淀, 北京, 中国 \\ asxxzliujieliujie@126.com, ${ }^{b} 1557516060 @ q q . c o m$ \\ 通讯作者
}

中文摘要. 本文从社会协同治理模式的生 发为起点, 认为此模式的选择动因有三点: 传统治理模式效能低下; 社会组织的巨大发 展; 中国共产党的执政主张。但也面临三个 困境: 社会治理理念落后; 社会发育程度不 高; 社会治理机制不健全。为此, 从三个方 面进行社会协同治理模式的建构: 转变传统
治理观念; 培养协同治理主体; 创新协同治 理机制。

关键词：社会协同；治理模式；现存困境；路 径探寻 


\section{1. 引言}

党的十八届三中全会明确提出了创新 社会治理体制、提高社会治理水平的新要 求, 因此积极贯彻落实十八大报告提出的党 委领导、政府负责、社会协同、公众参与、 法治保障的社会管理格局, 加快形成以寻求 公共利益与共同体普遍共识为目标的社会 协同治理模式成为了社会改革的当务之急 [1]。社会协同治理模式强调社会治理主体多 元化, 聚焦于解决公共问题, 实现公共利益 的最大化。

\section{2. 社会协同治理模式选择的历史逻辑}

\section{1 社会协同治理模式的生发}

自国家产生以来, 人类对于国家与社会 关系的思考就没有停止。马克思认为国家从 来不是一个绝对的、独立的观念存在, 是由 社会母体产生, 国家与社会的关系是随着生 产力水平的变化而变化 ${ }^{[2]}$ 。进而我们可以认 为, 生产力的发展决定着社会治理模式。在 原始社会, 由于生产力的极其低下, 人类的 社会关系简单而纯粹, 我们看不见国家存在 的标志, 更没有任何为了管理而存在的暴力 机构。我们看到的是风俗、族长的威信。那 么, 社会的自治是这个阶段的唯一治理模 式。这种模式要求行为者能够根据自己的理 性目标来指导生活, 而不是受到外在力量的 操纵, 也就是说自治的行为是出于实践理性 的行为。随着社会生产力的发展, 私有制的 出现以及社会分工的加速, 社会开始分化, 出现阶级对立, 进而导致利益冲突, 因而要 有一种第三方的力量来压制社会的公开冲 突, 这种第三方的力量就是国家。至此, 人 类社会进入了管理型的社会治理模式, 这种 治理模式建立在国家和政府的权威之上, 国 家和政府成为管理公共事务的唯一主体, 为 了维护统治阶级的意志和长远利益, 对社会 进行家长式管理。20世纪70-80年代, 生产 力进一步提升, 电子信息技术广泛应用, 经 济结构从商品生产经济转向服务型经济, 职 业分布以技术阶层的崛起为特征, 人类社会 进入了后工业社会。这个时候的社会公共服 务项目逐步增加, 社会环境复杂而多变, 政 府有限的财力与人民群众日益增加的需求
之间存在着越来越大的鸿沟, 政府疲于应对 复杂多变的社会事务。在这种情况下, 非政 府组织、私营部门、公民参与公共事务的机 会也与日俱增, 政府与社会其它主体间的合 作日益广泛和深入, 共同应对经济和社会问 题，社会协同治理模式由此生发。

\section{2 社会协同治理模式的内涵及特点}

协同治理理论的研究最早缘起于德国 物理学家赫尔曼・哈肯创立的协同学, 现在 协同理论被广泛用来解释复杂的社会现象。 近些年来我国社会学家也开始进行大量关 注。比较有代表性的俞可平认为 “国家与社 会协同治理的实质, 就是政府与公民对社会 政治事务的合作管理，简单地说，就是官民 共治” ${ }^{[3]}$ 。它有以下几个方面的特征: 一是 治理主体多元。政府不再是唯一的治理主

体，政府、市场、社会组织和公民可以直接 或间接地参与到社会治理中, 形成多元主体 共治的格局。二是治理主体平等。法律地位 平等, 不存在政府运用权力强迫对方服从的 情况。参与机会平等, 不存在某一治理主体 运用特权垄断的情况。三是治理过程互补。 各治理主体间通过上下互动进行高效合作， 达成公共利益最大化的治理目标。四是治理 途径灵活。面对多变而复杂的治理环境, 因 时、因地进行治理, 寻求最优解决途径。

\section{3. 社会协同治理模式选择的现实逻辑}

在我国深化改革的这样一个关键时期, 党和国家选择协同治理作为社会治理创新 的路径取向, 既充分考虑了社会治理的客观 需要, 也结合了当前我国社会建设的现实情 况。

\section{1 传统治理模式效能低下是协同治理模 式选择的根本动因}

近年来, 因各种社会矛盾而引发的群体性事 件不胜枚举, 主要围绕在劳工的工资纠纷引 发的罢工事件、失地农民的社会保障难以有 效落实、农民工子弟的辍学率居高不下等方 面, 导致这些问题长期以来得不到有效解决 的原因与政府的传统的治理模式不无相关: 一是管理手段单一，“命令一控制”的自上 而下的管理模式在遇到相关利益方存在根 
本性冲突时, 由于存在利益相关性而有失公 平、或者欺上瞒下、或者畏首畏尾, 显得效 率低下。二是管理方法僵化, 在多变的环境 中, 政府官僚化的思考和行为方式所体现出 非人性的僵化特征无法随着环境的变化而 及时进行调整, 造成社会治理效率低下。三 是获取信息滞后, 传统的管理型政府获取信 息的渠道往往是自下而上各级政府的反馈, 尤其是对于一些突发性事件, 不能够准确、 及时的做出判断, 延误了最佳处理时期。

\section{2 社会组织的巨大发展是协同治理模式 选择的必要前提}

党的十一届三中全会以后, 我国确立了 社会主义市场经济体制, 打破了计划经济时 代下形成的社会结构, 社会资源可以一定程 度的自由流动, 从而促进了国家与社会的分 离, 社会领域的相对独立和自主为公民社会 的发展提供了土壤, 尤其是社会组织的兴起 呈现逐年快速增长的趋势, 20 世纪60年代, 全国性社团不到100个，地方性社团约6000 个。而到了1989年, 全国性社团增长了 15 倍, 达到1600个, 地方性社团更是达到20 万个。2013年据民政部门统计, 到2012年, 全国社会组织数达 49.9 万个, 其中社会团体 27.1 万个, 基金会 3029 个, 民办非企业单位 22.5 万个 ${ }^{[4]}$ 。然而, 这些只是在官方注册的 组织数字, 实际数量远大于此, 在 2007 年时 俞可平估计就有 300 万个左右。

\section{3 中国共产党的执政主张是协同治理模 式选择的政治逻辑}

建国伊始, 我国《宪法》就规定中华人 民共和国的一切权力属于人民, 并对民间组 织持积极肯定的态度。改革开放以来, 我们 党更是对社会的建设进行了不解的努力与 探索。中国特色社会主义是亿万人民自己的 事业, 坚持人民主体地位、发挥人民主人翁 精神、尊重人民首创精神, 最广泛地动员和 组织人民到社会治理中来是我党在社会建 设中的一贯主张。党的十六届四中全会提出 了加强社会建设和管理、推进社会管理体制 创新和建立健全党委领导、政府负责、社会 协同、公众参与的社会管理格局。党的十八 届三中全会明确提出: 实现政府治理和社会 自我调节、居民自治良性互动; 促进群众在
城乡治理、基层公共事务和公益事业中实行 自我管理、自我服务、自我教育、自我监督。 这些要求突出了人民在社会治理中的主体 作用, 坚持了社会治理为了人民、依靠人民、 成果由人民共享, 并为民间组织的发展提供 了制度保障, 这是社会协同治理模式的政治 逻辑所在。

\section{4. 社会协同治理模式选择的困境}

综上分析, 我们可以看到社会协同治理 模式不但必要, 而且可行。但是现实的治理 模式依然没有改变以政府为中心的传统管 理模式, 这是因为推进社会协同治理模式面 临三个方面的困境:

\section{1 社会治理理念落后导致协同治理模式 缺乏思想基础}

多年来, 在旧的社会治理模式下, 无论 是政府, 还是社会都已经习惯了政府为主体 的单一社会管理格局。主要表现:一是政府 本位思想严重, 服务理念缺失。大一统的文 化思想以及建国后的计划经济发展模式, 造 成了政府全能、政府至上的行政理念, 忽视 了政府工作的服务性; 同时将社会治理看作 一种自上而下的治民活动, 未曾与非政府组 织、私营部门、公民合 作治理社会, 造成 了社会主体功能的萎缩。二是公民意识淡 薄。首先是权力意识的薄弱, 这里主要是指 公民对自身所拥有的权利认识不清, 缺乏主 动行使权利的热情, 诸如选举权、知情权、 监督权等。调查显示, 即使是受过高等教育 的大学生也只是有 $3.2 \%$ 的人非常熟知自己 的权利; 其次, 主体意识的缺乏。在政府家 长式的管理下, 社会依附国家、公民依赖政 府已成为社会生活的习惯, 导致公民缺乏当 家作主的意识, 常以事不关已的心态来看待 社会问题。

\section{2 社会发育程度不高导致协同治理模式 缺乏社会基础}

改革开放以来, 中国社会基本形成了以 党和政府官员为代表, 以党政组织为基础的 国家系统,或称政治社会; 以企业家为代表, 以企业组织为基础的市场系统,或称经济社 会; 以公民为代表,以民间组织或社会组织 
为基础的社会系统,或称公民社会 ${ }^{[3]}$ 。但公民 社会在现行社会治理模式下, 缺乏参与社会 治理的渠道和自我管理的能力, 发展速度远 滞后于其他两个社会, 没有成为社会治理的 一支重要力量。主要表现在:一是组织数量 少, 社会影响小。据统计, 2011年末我国每 万人拥有社会组织的数量仅仅为 3.4 家。而 美国为52家, 日本为97家, 法国为 110 家, 一些发展中国家如阿根廷为 25 家, 巴西为 13 家。二是角色错位, 功能紊乱。我国许多社 会组织由政府扶持, 在经费、人员以及运作 中与政府联系紧密, 并没有真正做到非官 方、非盈利、独立自愿, 有些行业协会甚至 演变为管理企业的第二政府; 三是社会组织 的相关法律法规不完善, 管理混乱 ${ }^{[5]}$ 。至今 仍没有出台一部关于社会组织的国家法律, 靠的只是国务院颁布的《条例》进行管理, 法律的空白让社会组织天生以来就缺乏合 法性, 混乱的管理极大的阻滞了其健康发 展。

\section{3 社会治理机制不健全导致协同治理模 式缺乏民众基础}

党的十六届四中全会第一次提出的社 会协同治理模式, 开启社会改革进程。但是, 作为社会协同治理模式关键的社会协同治 理机制的建设仍远远落后, 制约着社会协同 治理的实现。一是政府对社会组织的防范性 管理。政府由于担心与社会组织利益目标的 差异而造成政府施政的困难, 确立了对社会 组织进行 “分级等级、双重管理”管理体制, 将其限制于狭窄的活动空间。二是行政权力 划分不合理。行政职能范围过宽过广, 政府 的触角深入到社会的方方面面, 由此导致全 能政府对于社会治理的低效率、政府职能结 构不合理等弊端的产生 ${ }^{[6]}$ 。三是缺乏主体间 的联动机制。政府与社会是两个独立的系 统, 有各自的利益诉求。治理主体相互间工 作衔接和互动不足, 权限不明、职责不清、 越位并存, 缺少有效的合作机制, 将政府与 社会形成合力进行治理。

\section{5. 推进社会协同治理模式选择的路径探寻}

总结我国社会建设现状, 并结合当下的 世情、国情、党情, 进一步推进社会协同治
理模式的形成, 重点在于转变传统观念, 找 准各自定位; 培养协同治理主体, 发展公民 社会; 创新协同治理机制, 建构民众基础。

\section{1 转变传统治理观念, 找准各自定位}

任何模式、制度有效实施的前提，都是 要解决相关价值观念的问题。一是政府坚持 以人为本，把服务社会作为政府存在、运行 和发展的根本宗旨, 积极主动地对社会公民 的需求做出反应, 急社会之所需, 为公民和 社会提供及时、方便、周到的服务 ${ }^{[7]}$ 。同时 鼓励和支持社会各方更加积极、有效地参与 社会治理, 将一些政府没法管、不必要管、 管不好的社会事务交还给社会, 由原来的直 接管理转变为间接管理,向政府主导型的社 会共同治理模式转变。二是培养公民意识。 依托中国传统文化, 借鉴西方先进经验, 加 强公民意识教育，摆脱以往臣民意识，树立 公民观念; 培养社会成员对利益的主动追求 精神, 增强自主意识和平等意识; 依法维护 自身的合法利益。通过合作、互动积极协同、 配合政府维护社会秩序，优化资源供给，促 进社会的和谐发展 ${ }^{[5]}$ 。

\section{2 培养协同治理主体，发展公民社会}

协同治理需要有社会多元主体的充分 发育, 这是推进协同治理的社会基础: 一是 要完善社会主义市场经济和民主政治制度。 经济体制上改革以十八界三中全会精神为 指导, 处理好政府市场的关系, 建立市场在 资源配置中的决定性作用; 政治制度上改革 要扩大人民民主，健全民主制度，鼓励公民 政治参与、加快行政体制改革，从而进一步 打破国家对社会经济的垄断，实现社会资源 的最优配置, 为社会与个人的独立发展提供 空间。二是要大力发展公民社会组织。发展 社会组织要依靠制度创新, 改革现行登记管 理制度, 建设与社会发展相适应的组织文 化。政府创造宽松的社会环境, 主动调整与 社会的关系, 鼓励、引导社会组织的发展。 界定好社会组织、政府的各自边界, 避免政 府权力扩大化、社会组织行政化 ${ }^{[7]}$ 。三是要 建立健全相关法律法规。我们要立足于宪法 结社自由的宗旨, 结合我国当前社会发育的 实情, 研究制定社会组织的一般法律, 取消 重复的规定和条例, 对各社会治理主体地 
位、主体资格、活动原则、监督管理等方面 作出明确规定, 为社会的健康发育提供有力 的法律依据。

\section{3 创新协同治理机制，建构民众基础}

完善的协同治理机制是政府与社会能 否形成良好互动的关键所在。一是要构建政 府社会信任机制。首先要培养政府与社会的 伦理自觉性和道德自律性, 这是建立政府与 社会信任机制的内在基础 ${ }^{[8]}$ 。其次是建立信 息沟通制度。协同主体之间通过信息的公开 与沟通机制, 建立牢靠与可预见的信任感。 再次是建立双向监督制度。无论是政府还是 其他社会主体, 由于自身理性经济人的一面 会促使他们为了自身的利益, 滥用相互之间 的信任而损害公共利益。因此双方之间必要 的监督机制, 能够将协同治理所带来的的风 险和损失降到最低。二是构建政府放权机 制, 首先要厘清政府、市场和社会三者之间 的合理边界。政府直接提供基本的社会保障 制度和系统, 例如基本住房、基本医疗、基 础教育和基本养老等, 承担公平和公正的社 会责任; 由社会自我治理的, 社会充满活力 的, 如没有法律法规依据的登记、年检、年 审、监制、认定等管理措施, 这部分政府要 放权, 做好引导与监督工作。其次建立权责 对等监管机制, 不能把放权的过程简单理解 为只是权力的下放, 还要考虑在社会运行过 程里建立起规范和约束的机制, 该回归社会 的真正能回归到社会。三是要完善政府社会 合作机制。政府需要建立健全社会在治理过 程中的制度化沟通渠道和参与平台, 构建民 主协商沟通、平等合作、互惠互利互助、利 益表达与综合协调以及矛盾化解等机制, 促 进政府与公民、社会各阶层间、公民与公民 间合作, 理顺各种关系, 避免重大的社会冲 突, 实现社会生活的安定有序 ${ }^{[9]}$ 。

虽然当代中国的社会协同治理模式仍 不成熟, 但它毕竟揭示了社会治理的未来路 径与趋势。开放的社会预设了开放的课题, 变革的时代呼唤着创新的思维。我们期待着 通过政府、社会、公民之间共同努力, 能够 形成真正的良性互动, 进而达到治理的 “善 治”。

\section{References}

[1] Zheng Qiao, Xiao Wen. Synergetic Go vernance: A New Logic of Service-ori ented Government. Chinese Public Ad ministration, vol.7, pp.48-53: 2008

[2] Yin Zhaoju, The Emerging of Civil S ociety and Its Significance to Governa nce in Reform China. Guangzhou: Gu angdong People's Publishing House. 20 11

[3] Yu Keping. Reconstructing the Social Order and Moving Towards A Co-gov ernment of Official and People. Journa 1 of China National School of Admini stration 2012

[4] Yu Keping. The Rising-up and Chang es of Governance of China' s Civil S ociety. Beijing: Social Science Acade mic Press. vol.4, 2002

[5] Hou, Yifu. Development of China's Civil Society-Current Situation, Probl em and Prospect. Heilongiiang: Heilon gjiang University Press. 2009

[6] Zhou Zhiren. Characteristics of Chines e Administrative System and Improve ments of Government Functions. Realit y Only. 6.1997

[7] Pang Juan. Probe on the Equalization of Basic Public Service and the Const ruction of Service-oriented Government. Journal of Beijing Electronic Science and Technology Institute. vol.3,2010

[8] Ou Liming. Cooperative Governance:T rust Relation and Platform Constructio n. ,Chinese Public Administration,vol.5 2009

[9] Ma Jianzhen. Cooperative Governance and Innovation of China' s Social Ad ministration Mode. Journal of Nanjing University of Aeronautics and Astron autics (Social Sciences). 2012 